\title{
Embedding the United Nations sustainable development goals into energy systems analysis: expanding the food-energy-water nexus
}

\author{
Taco Niet ${ }^{1^{*} \mathbb{D}}$, Nastaran Arianpoo ${ }^{2}$, Kamaria Kuling $^{1}$ and Andrew S. Wright ${ }^{2}$
}

\begin{abstract}
Background: There have been numerous studies that consider the nexus interactions between energy systems, land use, water use and climate adaptation and impacts. These studies have filled a gap in the literature to allow for more effective policymaking by considering the trade-offs between land use, energy infrastructure as well as the use of water for agriculture and providing energy services. Though these studies fill a significant gap in the modelling literature, we argue that more work is needed to effectively consider policy trade-offs between the 17 United Nations sustainable development goals (SDGs) to avoid missing important interactions.

Results: We examine the 17 SDGs individually to determine if it should be included in a modelling framework and the challenges of doing so. We show that the nexus of climate, land, energy and water needs to be expanded to consider economic well-being of both individuals and the greater economy, health benefits and impacts, as well as land use in terms of both food production and in terms of sustaining ecological diversity and natural capital. Such an expansion will allow energy systems models to better address the trade-offs and synergies inherent in the SDGs. Luckily, although there are some challenges with expanding the nexus in this way, we feel the challenges are generally modest and that many model structures can already incorporate many of these factors without significant modification.
\end{abstract}

Finally, we argue that SDGs 16 and 17 cannot be met without open-source models and open data to allow for transparent analysis that can be used and reused with a low cost of entry for modellers from less well-off nations.

Conclusions: To effectively address the SDGs, there is a need to expand the common definition of the nexus of climate, land, energy, and water to include the synergies and trade-offs of health impacts, ecological diversity and the system requirements for human and environmental well-being. In most cases, expanding models to be able to incorporate these factors will be relatively straight forward, but open models and analysis are needed to fully support the SDGs.

Keywords: Energy modelling, UN sustainable development goals, Food-water-energy nexus, Sustainability, Policy

*Correspondence: Taco_Niet@sfu.ca

${ }^{1}$ School of Sustainable Energy Engineering, Faculty of Applied Science, Simon Fraser University, 10285 University Dr., Surrey, BC V3T 4B7, Canada

Full list of author information is available at the end of the article permits use, sharing, adaptation, distribution and reproduction in any medium or format, as long as you give appropriate credit to the original author(s) and the source, provide a link to the Creative Commons licence, and indicate if changes were made. The images or other third party material in this article are included in the article's Creative Commons licence, unless indicated otherwise in a credit line to the material. If material is not included in the article's Creative Commons licence and your intended use is not permitted by statutory regulation or exceeds the permitted use, you will need to obtain permission directly from the copyright holder. To view a copy of this licence, visit http://creativecommons.org/licenses/by/4.0/. The Creative Commons Public Domain Dedication waiver (http://creativeco mmons.org/publicdomain/zero/1.0/) applies to the data made available in this article, unless otherwise stated in a credit line to the data. 


\section{Highlights}

- Nexus modelling needs to be expanded to address the United Nations sustainable development goals.

- Human well-being, health, ecological diversity, and natural capital all need to be included in nexus analysis.

- Sustainable development goals 16 and 17 require open-source models and open data to empower development.

\section{Introduction}

The United Nations (UN) sustainable development goals (SDGs), adopted by the UN in 2015, provide a roadmap for 17 areas of focus for international development [1]. The SDGs can be applied both by countries to track and address internal development goals, and by the UN and other agencies to direct development funds. One challenge that becomes apparent after even a cursory examination of the SDGs is that each goal is inextricably linked to many of the other goals. For example, goal 2: zero hunger can likely not be met without addressing goal 1: no poverty, and vice versa. As another example, McCollum et al. [2] provide an analysis of the interactions between goal 7: clean and affordable energy and each of the other goals and find that essentially every goal has at least some interaction with goal 7.

At the same time, energy systems modellers have begun to recognize the interactions between different sectors, what many refer to as modelling the 'nexus'. Recent work has begun to incorporate energy planning with land and water use planning to address the 'nexus' between these different sectors and their climate and environmental impacts. These integrated modelling frameworks address some of the interactions between these sectors and allow for more effective decision-making. As an example, a nexus modelling study for the city of New York found that many energy-saving strategies increased water use and vice versa [3]. Only by studying the interactions between the different nexus aspects can these trade-offs, as well as potential synergies, be effectively identified, addressed, and mitigated.

Though the energy systems modelling literature to date has contributed to addressing the trade-offs at the nexus of land, water, energy and climate, we argue that there is a need to consider other socio-environmental trade-offs than have been, to date, incorporated into such models. Specifically, we argue that there is scope to incorporate many different aspects of the SDGs into systems models and to thereby identify both trade-offs between policies and identify beneficial synergies. Such a structured approach to incorporating different aspects of the SDGs into systems modelling would contribute to better policymaking.

In this paper, we review each of the 17 SDGs and identify specific linkages of each to energy systems modelling and specifically, the integration of the SDGs into either techno-economic capacity optimization models or energy-economy type models. In many cases specific connections between the SDG and these existing system models can be identified. In this case, we attempt to describe the specific linkage that could be incorporated into the model framework. In other cases, the links are more conceptual and only general principles are identified. This builds on the work by McCollum et al. [2] who identify specific linkages between goal 7 , clean and affordable energy, and each of the other goals but, in this paper, we focus on the ability to incorporate aspects of each goal into energy systems models rather than the linkages between the goals.

We start this paper with some background on the SDGs and the modelling of the SDGs to date. We then review each of the 17 SDGs and discuss how or if each goal can be incorporated into systems models. We summarize these discussions in an overview table that identifies two aspects of each goal: the importance of including aspects of this goal in systems models and the ease with which these aspects can be modelled.

\section{Background}

The SDGs (Fig. 1) were adopted by the United Nations in 2015 and are aspirational goals that guide nations, UN departments and countries in how to focus their development efforts. Each goal expresses an overarching challenge to sustainable development. To further assist in measuring and addressing the goals, they are sub-divided into a total of 168 sub-goals. Although incorporating the goals into energy systems models will likely address some aspects of the sub-goals better than others, in this work we focus on an overarching analysis of the 17 goals to provide focus for modelling efforts. As energy systems models develop that address aspects of the goals, focus can shift to confirming which sub-goals are incorporated and if there are gaps in addressing the sub-goals.

Incorporating the SDGs into energy system modelling, to date, has focussed mainly on incorporating land, energy, water, and climate into optimization modelling frameworks. Energy systems modelling can be classified into three broad classes: energy-economy, capacity expansion/optimization and power systems modelling. Energy-economy modelling attempts to address the economy-level interactions between sectors and incorporate consumer behaviour, but cannot represent specific technological detail. Capacity expansion modelling is 


\section{SUSTAINABLE G
DEVELOPMENT G}
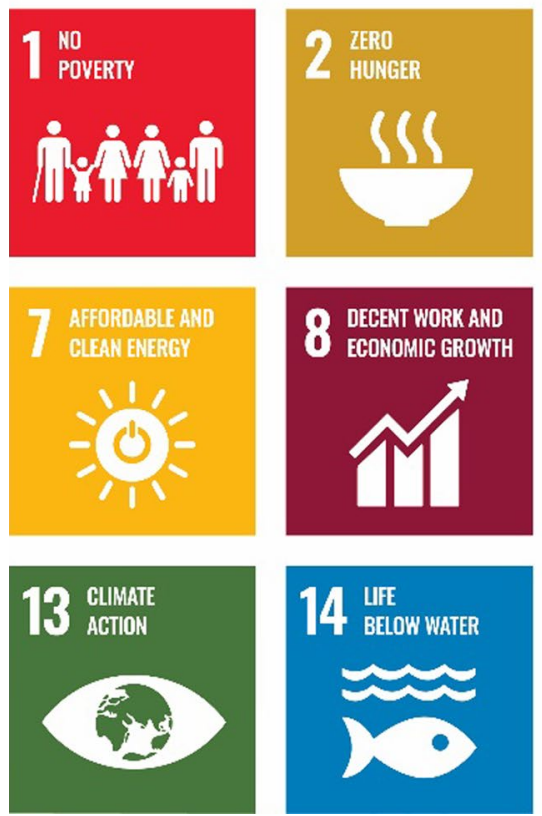

Fig. 1 The sustainable development goals
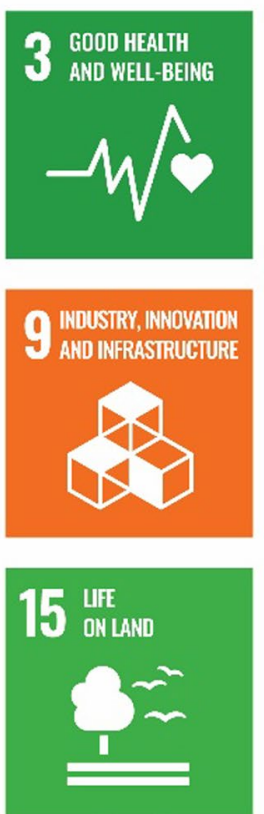
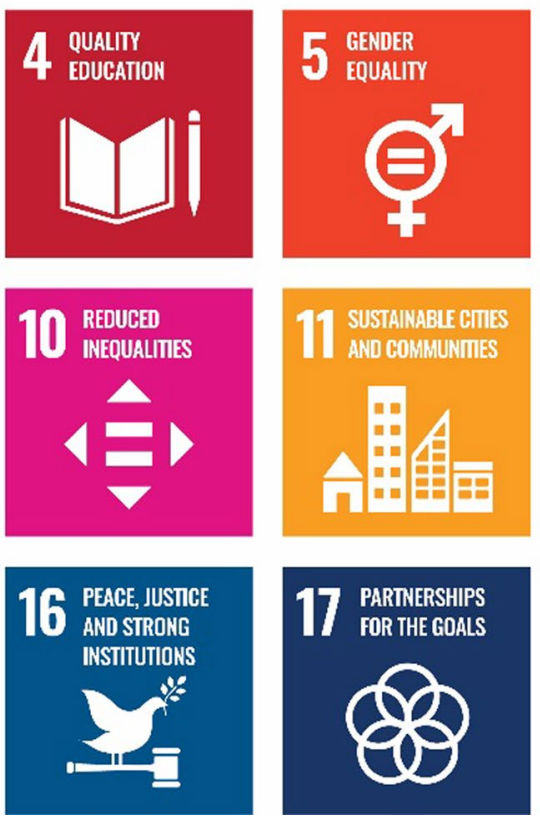
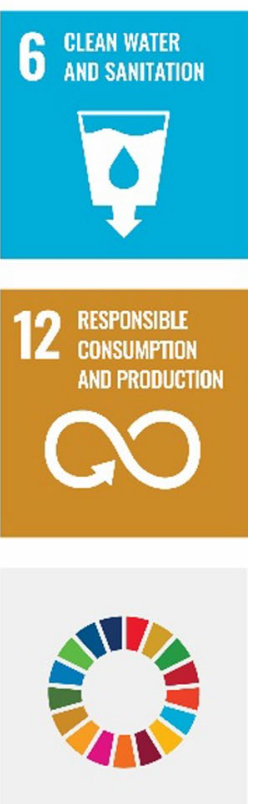

applied to large-scale system optimization to determine a 'best' system to meet given criteria, and power systems modelling is designed to assess the power system stability and operational considerations. In all cases, the overarching purpose is to identify development paths that will maximize welfare/profits while reducing unwanted consequences. Work to address the interactions between the SDGs into capacity expansion/optimization models includes the climate, land, energy and water systems (CLEWs) modelling framework $[4,5]$ and the NExus Solutions Tool (NEST) framework [6, 7]. These models are designed to choose the optimal development path within the constraints and trade-offs defined in the model structure. Stylianopoulou et al. [8] provide an overview of similar water-energy-food nexus models that have been applied in the literature. These modelling efforts begin to address the nexus between goal 7 (energy), goal 2 (zero hunger), goal 6 (clean water and sanitation) and goal 13 (climate action) but do not, as yet, expand beyond these four goals.

There are a few other energy systems modelling approaches in the literature that incorporate different aspects of the SDGs. Deane and Brinkerink [9] used the combination of the Global Change Assessment Model (GCAM) [10], a partial equilibrium energy-economy model with PLEXOS [11], a power systems model, to address interactions between goal 8 (economic wellbeing) with goal 7 (affordable and clean energy). GarcíaGusano [12] links a life cycle assessment model to a power system planning model to incorporate the life cycle impacts of the power sector into a capacity expansion model. Galli et al. [13, 14] similarly incorporate a life cycle assessment model into an input-output energyeconomy model, addressing goal 8 (economic well-being) with aspects of goals 13, 14 and 15 (climate action, life under water and life on land). Other approaches to footprint analysis likewise attempt to incorporate diverse impacts [15-17], but generally do not include the decision-making structures that are the major features of energy systems models. Overall, each of these efforts attempts to add some aspect of the SDGs in energy system modelling, but no comprehensive approach to which goals need to be included has been published in the literature.

\section{Modelling the UN sustainable development goals}

In this section, we review each SDG and, from the perspective of systems modelling, consider if any aspects of the goals need to be incorporated into systems models. For each goal we focus first on the importance of 
Table 1 Icons for ranking SDGs for modelling

\begin{tabular}{cc}
\hline Importance of modelling & Not important \\
& Some modelling required \\
Modelling critical to meeting goal & Easily included in systems models \\
Ease of modelling & Some modelling challenges \\
& Unclear how to include in systems models \\
\hline
\end{tabular}

addressing aspects of the given goal in an energy systems model and then, where possible, identify how aspects of the given goal can be incorporated into an energy systems model. In some cases, although it may not be directly possible to incorporate aspects of a goal into a systems model, the goal highlights principles that should be followed in developing models. Following on the work of the International Science Council [18], van Soest et al. [19] and Pradhan et al. [20], we also attempt to identify linkages and feedbacks between the SDGs that may need to be considered when modelling, but we do not repeat this work of identifying linkages between the different goals. Table 2 provides a summary of the ranking for each SDG in each category to summarize the overall discussion.

Table 2 Summary of the SDGs and the ability to address aspects of this SDG in a modelling framework

\begin{tabular}{|c|c|c|c|c|}
\hline \multicolumn{2}{|c|}{ Sustainable Development Goal } & $\begin{array}{l}\text { Importance of } \\
\text { Modelling }\end{array}$ & $\begin{array}{c}\text { Ease of } \\
\text { Modelling }\end{array}$ & Type of Model(s) Required \\
\hline $1_{\text {max }}^{\text {max }}$ & No Poverty & & & Energy-Economy \\
\hline 2 isis & Zero Hunger & & & Optimization \\
\hline$-1 \sqrt{6}$ & Good Health and Well-being & & & $\begin{array}{l}\text { Energy-Economy, } \\
\text { Optimization }\end{array}$ \\
\hline 4 midum & Quality Education & & & $\mathrm{N} / \mathrm{A}$ \\
\hline 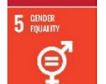 & Gender Equality & & & $\mathrm{N} / \mathrm{A}$ \\
\hline 6 & Clean Water and Sanitation & & & Optimization \\
\hline $7=$ & Affordable and Clean Energy & & & $\begin{array}{l}\text { Optimization, Energy- } \\
\text { Economy }\end{array}$ \\
\hline T1 & $\begin{array}{l}\text { Decent Work and Economic } \\
\text { Growth }\end{array}$ & & & Energy-Economy \\
\hline 8 & $\begin{array}{l}\text { Industry, Innovation and } \\
\text { Infrastructure }\end{array}$ & & & $\begin{array}{l}\text { Energy-Economy, } \\
\text { Optimization }\end{array}$ \\
\hline 10 parken & Reduced Inequalities & & & $\mathrm{N} / \mathrm{A}$ \\
\hline A 斯隹国 & $\begin{array}{l}\text { Sustainable Cities and } \\
\text { Communities }\end{array}$ & & & $\begin{array}{l}\text { Optimization, Energy- } \\
\text { Economy }\end{array}$ \\
\hline 12 ab & $\begin{array}{l}\text { Responsible Consumption } \\
\text { and Production }\end{array}$ & & & Optimization \\
\hline Q & Climate Action & & & $\begin{array}{l}\text { Optimization, Energy- } \\
\text { Economy }\end{array}$ \\
\hline$\underset{5}{14}$ & Life Below Water & & & Optimization \\
\hline 15 of & Life on Land & & & Optimization \\
\hline 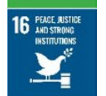 & $\begin{array}{l}\text { Peace, Justice and Strong } \\
\text { Institutions }\end{array}$ & $\Omega$ & & Open source models \\
\hline 17 & Partnerships for the Goals & & & Open source models \\
\hline
\end{tabular}


For each SDG, beside the SDG icon, we provide three items: modelling required; ease of modelling; and model structure(s) required. The ranking and icons used are summarized in Table 1 . The first, modelling required, is an indication of the importance of including this goal in an energy systems model, to indicate how important feedbacks and interconnections are to addressing this goal. Modelling required is ranked on a three-point scale, with a white icon indicating this goal does not need to be considered or that it is better addressed in other ways; a light blue icon indicating that some modelling may be required, and a dark blue icon indicating that it is not clear how this goal would be addressed without incorporating factors into models. For example, goal 7, access to clean and affordable energy is ranked dark blue as it is core to most systems models and, without systems modelling it is not clear how this goal can be addressed. The second item, ease of modelling, indicates how easily aspects of this goal can be incorporated into energy systems models. The ease of modelling is ranked on a threepoint scale, with a green icon indicating it can easily be modelled, an orange icon indicating some modelling challenges, and a red icon indicating it is not clear how to model this specific goal. For example, goal 6, clean water and sanitation, is ranked green as it is relatively easy to incorporate into modelling frameworks by tracking both the water needs, and the energy and water supplies required to provide this. Finally, we identify which model structures (energy-economy, optimization) are best suited to addressing this goal.

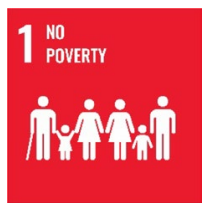

Modelling Required:
Ease of Modelling:
Model Structure: Energy-Economy

The ability to establish a policy that reduces poverty relies on an effective and accurate understanding of the interactions between policy and economic development. In general, from a systems modellers' perspective, this mainly focusses on broader questions such as how to ensure economic development and how to ensure access to affordable services. Energy-economy models, broadly, address the first issue: how to ensure economic development to help lift people out of poverty and are well-established tools for modelling broad economic development. The importance of including poverty reduction policies in economic models to consider the feedbacks between such policies and overall economic health means this SDG is categorized as modelling required in terms of the importance of modelling to address this goal and, in fact, most systems models include some form of economic indicators in their model formulation.

We rank this SDG as challenging to include in systems models since there are significant challenges for modelling to address poverty across all levels of society. These challenges are addressed in a variety of ways in the social sciences literature [21-23]. The challenge that systems modelling has in addressing the distribution of wealth, as well as the evidence of social sciences approaches to some of these challenges, is addressed further in goal 17: partnerships towards the goals.

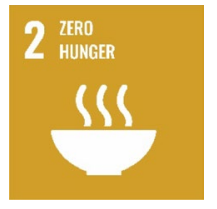

Modelling Required:

Ease of Modelling: $\bigcirc$;

Model Structure: Optimization

Zero hunger requires both adequate food production, on average, and resilience to weather events that might impact crop yields locally. Adequate food production, including consideration of expected crop yields and consideration of economic ability to purchase and maintain farm equipment such as tractors, irrigation systems and fertilizer are considered in existing optimization modelling frameworks including the CLEWs framework which has been applied in many different contexts and different scales around the globe including cross-boundary jurisdictions such as the Drina river basin [24, 25], for the countries of Mauritius [4] and Burkina Faso [26] as well as for the city of New York $[3,27]$. Given the existence of models that directly address food availability, we rank this goal as definitely required to be considered in modelling structures and easy to incorporate into optimization modelling paradigms.

To further reinforce the fact that this goal needs to be considered in systems modelling, it should be noted that this goal is the most interconnected goal of all 17 as identified by the International Council for Science [18], with strong interconnection to eight other goals. Such strong interconnections mean that there are likely many ways that this goal will be incorporated into systems models and that different model structures will likely highlight different synergies and trade-offs.

One piece of the zero-hunger goal that is not well addressed by existing model frameworks is the resilience of agricultural production with extreme weather events and future expected yields under climate uncertainty. There is some work in this area from the Food and Agriculture Organization and IIASA in the Global Agro-Ecological Zones database [28], where global yield predictions for various climate change scenarios are available but, overall, there is still significant uncertainty in this space. 


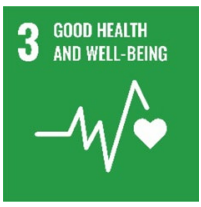

Modelling Required: $\bigcirc$;
Ease of Modelling:

Model Structure: Energy-Economy,Optimization

There has been significant work in quantifying the health impacts of various industrial activities in the literature, and there are many examples of both negative and positive health impacts of development. The challenge, then, is to adequately quantify the health impacts of different activities and track both the positive and negative health impacts in a model structure and determine how to incorporate these different aspects into systems models. A related challenge is modelling the environmental impacts of health-care-related activities such as the impact of waste from health, water and energy use, etc. Hensher [29] provides an overview of the literature on environmental impacts of health care which also needs to be incorporated into modelling structures.

Health impacts can be incorporated into modelling in two different ways. First, energy-economy models can incorporate the negative economic impacts on overall productivity. Second, capacity expansion models can include direct costs and impacts of decision on health. This would incur additional costs and a cost-benefit analysis could be undertaken to determine the best policy moving forward.

Although there is significant scope for including health and well-being impacts in systems modelling frameworks, the literature does not have many examples of this type of work. Lott et al. [30] incorporate the impacts of particulate matter into an energy system model, Shih and Tseng [31] find the co-benefits of efficiency measures are more cost-effective when health impacts are taken into consideration, and Zvingilaite [32] includes health and other externalities in a model for siting energy generation. These studies appear to be stand-alone studies and do not provide an overall modelling structure that incorporates health impacts in a systemic and ongoing way.

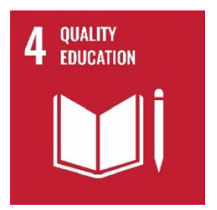

Modelling Required: $\bigcirc$;

Ease of Modelling:

Model Structures: -

Although quality education is crucial for meeting many of the other goals, and some aspects of education could potentially be included in model frameworks (such as the availability of labour in energy-economy frameworks), the overall structure of most models would not easily incorporate quality education into a systems model. As such, the Ease of Modelling for goal 4 is ranked as unclear with the red icon.

That being said, there are links between quality education and the other goals, specifically goal 7 which McCollum et al. [2] notes are critical for schools to have access to lighting, space conditioning and modern electronics. Overall this goal is relatively challenging to model, and it is not clear, other than the interaction between available human capital and education and the demands for energy services, how this could be incorporated into any modelling framework.
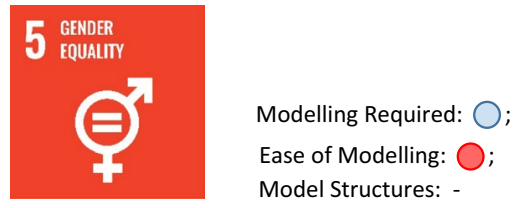

Similar to goal 4 , goal 5 of gender equality is very challenging to model in any systems modelling framework. And, like goal 4, there are some aspects such as labour availability that would contribute to GDP and therefore be able to be included in certain model structures, but these are not clear and direct links. Therefore, this goal is ranked as unclear how to model with the red icon. However, as modellers build their model structures to consider other goals, it is important that they consider the gender equality implications of the other aspects of their models.

For example, there are many aspects of the gender equality that are reliant on different aspects of systems models. McCollum et al. [2] note that access to energy services such as lighting and clean cooking can greatly enhance gender equity. The linkage to zero hunger is also an aspect of gender equality-when there is enough food available and the effort required to gather and prepare food is reduced, there is generally lower gender inequality in societies [18]. Given these interactions, we rank this goal as some modelling required. The model structures best suited to considering these interactions are identified in the other goals, namely goal 7, clean and affordable energy and goal 2 zero hunger.

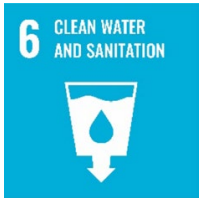

Modelling Required: $\bigcirc$;

Ease of Modelling: $\bigcirc$;

Model Structures: Optimization 
Access to clean water and sanitation is both an important goal in and of itself and is identified as linked to goal 2 , no poverty, and goal 7, affordable and clean energy by the International Council for Science [18]. Since this goal is so critically interconnected with two other goals, and there might be significant trade-offs between different and competing water demands, we rank this goal as critical to be modelled, with a dark blue circle.

Luckily, this goal is also one of the more easily modelled goals and has, in fact, been incorporated into a number of optimization modelling frameworks already, namely the CLEWs $[4,5]$ and NEST $[6,7]$ frameworks. Since this goal has already been incorporated into several existing models this goal is ranked as easy to include in systems models.

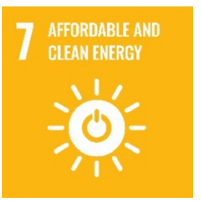

Modelling Required: $\bigcirc$;

Ease of Modelling: $\bigcirc$;

Model Structures: Optimization,Energy-Economy

Energy models have, for many years, been the core of modelling for sustainable development. Optimization models are used to determine the best and most costeffective paths for meeting projected energy demands, and energy-economy models are used to project demand changes based on economic growth, elasticities of substitution and other feedbacks. The International Council for Science identifies goal 7 as the second most interconnected goal, with links to goals $1,2,3,6,8$ and 13 [18]. Examples of such interactions include the health impacts (goal 3) of using biomass for cooking as compared to using electricity, or the negative impacts lack of electricity has on industrial development and job creation (goal 8 ). Given these large number of interactions, goal 7 needs to be incorporated into most model frameworks and, in fact, we see that most model frameworks consider affordable energy as one of the driving factors in the analysis.

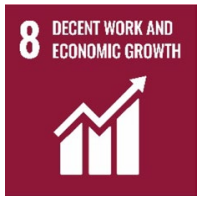

Modelling Required: $\bigcirc$

Ease of Modelling:

Model Structures: Energy-Economy,Optimization

There are two inter-related pieces to goal 8. The first, economic growth, is generally modelled with energyeconomy models. This is, however, challenged by the decent work part of the goal. Although the energy-economy structure can model the overall economic growth, the ability to incorporate aspects of decent work into the goal is more challenging.

The International Council for Science [18] connects this goal to goal 7, affordable and clean energy, goal 3, good health and well-being, and goal 14, life below water. The linkages to affordable energy and good health are clear; this goal might be better addressed by incorporating aspects of those goals into the modelling framework. Overall, this goal might need some modelling to be considered, and there are some challenges in modelling this goal effectively. McCollum et al. [2] state that strong institutions, especially financial, and energy infrastructure are critical for this goal and therefore the main modelling for this goal is likely to be incorporated by addressing goal 7 .
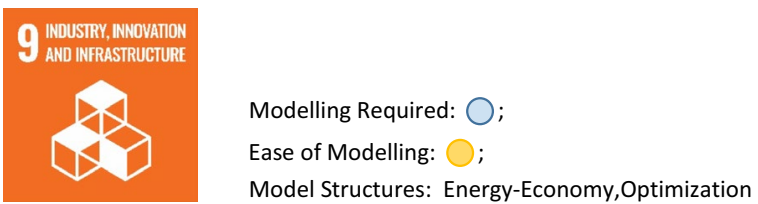

The discussion here is almost identical to the discussion for goal 8. Though there might be some aspects of innovation and industry that need to be modelled specifically, in many cases, systems models would not be required to address specific aspects of this goal, and many aspects of this goal can be included by considering goal 7 .

One aspect of systems models that may need to be expanded is the focus of optimization models on energy infrastructure. Expanding these models to include consideration of technology and innovation in other industries and sectors would enhance the ability of systems models to guide policy and decisions towards sustainable industrialization. A focussed expansion of such models may allow them to provide more context about goal 9.

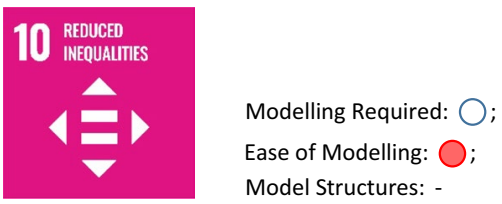

Similar to goals 4 (quality education) and 5 (gender equity), goal 10 is very challenging to model, and it is not entirely clear how this could be incorporated into any existing systems modelling frameworks. Nor is it clear what changes to model inputs would occur with increased equity in society. McCollum et al. [2] identify only weak links to energy in their analysis of the interactions with goal 7 (affordable and clean energy) and note that, in many cases, there are potentially both positive and negative impacts of energy on this goal. Overall, though consideration of equity is needed when discussing 
policies and their impacts on a system, it is unlikely that there will be any easy ways for this goal to be incorporated in systems models.

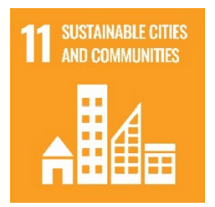

\section{Modelling Required: $\bigcirc$;}

Ease of Modelling: $\bigcirc$;

Model Structures: Optimization,Energy-Economy

Sustainable cities and communities require energy, food, welfare and good health and many aspects of the other goals. For example, McCollum et al. [2] identify that energy is an active driver of ensuring access to basic housing and ensuring that food preparation can be done in sustainable and healthy ways. However, there are some challenges in incorporating city and communityspecific aspects of systems into larger systems models. There is opportunity to do so in some cases, and there are examples in the literature of applying systems models to cities and communities (CLEWs in New York [3], A water-energy nexus study of Shanghai [33], A study of the Latrobe Valley near Melbourne, Australia [34]). In many cases, it is not needed to include community-specific features into a broader systems model, and it is often challenging to get data at a disaggregated enough level to be useful for analysing communities and cities in a broad systems context. As such, we rate this goal as some modelling required, but not easy to incorporate into larger systems models.

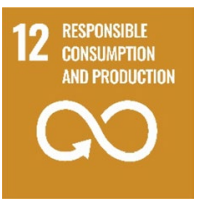

Modelling Required: $\bigcirc$;

Ease of Modelling:

Model Structures: Energy-Economy,Energy-Economy

Responsible production and consumption are embedded in many of the other sustainable development goals and, in that way, a large portion of this goal is already being modelled. For example, sustainable farming practices are indirectly referenced in goal 13 , climate action, goal 3, good health and well-being, and goal 7 , clean and affordable energy. However, there are some aspects of this goal that are likely not well considered in most existing modelling frameworks other than by exogenous parameters. Such exogenous methods of incorporating these parameters into a modelling framework may be the only practical way to include this goal in most models.

However, given the importance of consumer decisions in achieving goals such as climate action and good health and well-being, it is likely that this goal could use more attention. The use of intangible costs in the CIMS model [35-37] to determine consumer behaviour is an example of incorporating this goal directly into a modelling framework, but this does not exist broadly in different energy systems models. This goal has been rated some modelling required to reflect this and it is also rated as moderately difficult to incorporate.

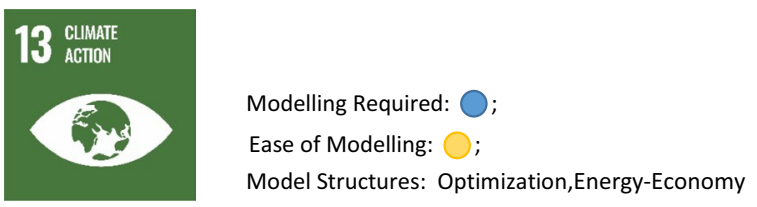

Achieving the climate action goal requires addressing the two different, but equally critical, notions of climate mitigation and adaptation in systems models. Mitigation needs to be considered by incorporating the impacts of the energy and other systems into the modelling framework. This is already done for most systems models, and it is common for model outputs to include costs for reducing carbon dioxide emissions. This gives this goal a rating of modelling required, and also relatively easy to incorporate this into most systems models.

The second aspect of this goal is climate adaptation. This is much harder to model as there is much uncertainty in the impacts of climate change, both on the environment and on society. As an example, there are databases that provide expected attainable crop yields available for various locations such as the global agroeconomic zones database [28]. This database has a baseline expected attainable yield and then several different potential yield trajectories. We are not aware of any current work that uses the projected changes in yields to model system dynamics, and there is a significant data management challenge should this be attempted. Other studies have also found that lowered crop yields due to climate change in Africa could reduce GDP growth and cause damage to human health [38]. So, although the mitigation aspect of this goal is relatively easy to model, we rank this goal as a moderately challenging to model due to the challenges of incorporating adaptation into systems models.

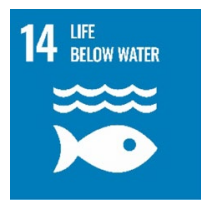

Modelling Required: $\bigcirc$;

Ease of Modelling:

Model Structures: Optimization

This goal is relatively situation specific. For example, if building a hydro dam is being considered in the model, 
then this goal must be modelled in some direct ways. However, many interactions of the energy system with life beflow water are driven by either food production from seafood or by the effluent from energy services and generation systems that impact life below water. Although it is important for systems models to be constrained so only sustainable amounts of seafood are available in model outputs, and it is important to track and mitigate emissions and effluent from power systems, overall, this goal does not need a large amount of modelling.

Since some interactions can be cumulative, such that one power plant may not impact the fish stocks in a lake, but multiple plants at the same location could reduce the sustainability of the fish in the lake, there are some challenging threshold effects that may need to be modelled. This makes it somewhat challenging to model this goal in most existing modelling frameworks.

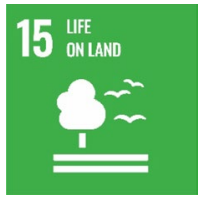

Modelling Required: $\bigcirc$;

Ease of Modelling: $\bigcirc$

Model Structures: Optimization

Goal 15 has some significant similarities to goal 14 in that sustainable land use, in some cases, requires tracking and identification of limitations of the productivity of the land base. However, in contrast to goal 14, humanity has a significant presence on land and has been adapting and changing land use for millennia. From farming to building cities and roads to open-pit mining to flooding large areas of land for irrigation and/or power generation, humanity has an inordinately large impact on land when compared to life below water. This goal interacts with many of the other goals, including goal 2 of no hunger. As such, we rate this goal as definitely requiring modelling as humanity's interactions with land and life on land are so vast.

Luckily, there are modelling structures existing in the literature, such as the CLEWs [4] model that incorporates land use planning in the model formulation. One challenge with the current CLEWs model framework that is not addressed well at this point is a lack of acknowledgement of the life on land, as the current CLEWs methodology focusses mainly on food production and productive use of the land base. Including factors such as the natural capital of forests and grasslands, as well as pastureland, and including consideration of the cumulative impact of land use changes would enhance the ability of the CLEWs framework to address this goal directly. Although there are some challenges with addressing this goal within a modelling framework, we rank this goal as relatively easy to model, given that there are existing frameworks that address most aspects of this goal.

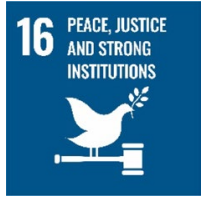

Modelling Required: $\bigcirc$;

Ease of Modelling: $O$;

Model Structures: Open Source

It is not clear that there is any way to incorporate peace, justice, and strong institutions into any existing modelling frameworks in any meaningful way. There is the potential to include higher costs of given policy decisions due to lack of effective institutions in a given jurisdiction and the resulting lower efficacy of the given policy within the society, but this would be challenging, and it is unclear how to justify any given level of reduced efficacy. On the other hand, the existence of peace and justice would contribute to enhanced GDP growth, but again, the link is indirect and not easy to quantify. As such, we rate this goal as very challenging to model in any meaningful way.

Having said that, we also feel that there is little value in attempting to incorporate this goal into a modelling framework. There may be some strengthening of institutions required to meet this goal in given jurisdictions, but this is likely more effectively addressed through foreign aid in building institutions rather than incorporating this into a given model structure.

There is one aspect of this goal that does impact on modeller decision-making, however, and that is the ability of institutions in a given jurisdiction to have access to the tools and models for effective decision-making. Models which are not accessible, and which cannot be modified and used for policy analysis in various jurisdictions, and/or models which do not provide open data to enable repeatable analysis reduce the ability of governments to have strong and effective policy decision-making support. As such, having open models and open data, and transparent decision-making for repeatable and reliable systems analysis is critical to meeting this goal. Luckily there are already a number of models that are available open-source, and there are groups of modellers working together on open-source and transparent modelling [39-41].

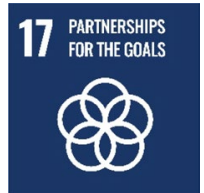

Modelling Required: $\bigcirc$ Ease of Modelling: $\bigcirc$; Model Structures: Open Source 
As with goal 16, goal 17 has no specific aspects that can be incorporated into modelling structures directly. This means that we rate this a challenge to incorporate any aspects of this goal into a modelling framework. Moreover, as with goal 16, goal 17 has no specific aspects that necessarily need to be incorporated into a modelling framework, and this is therefore rated as no modelling required.

One other aspect of having strong partnerships for the goals is the ability of modellers to use and share their models, and to aid each other in moving modelling forward. This, again, argues for open-source models, open data, transparent processes and clearly documented processes. There are examples of open-source models being used by partners for sustainable development, such as the capacity development work done by the United Nations Department of Economic and Social Affairs [42]. These initiatives, using open models that focus on transparency allows policymakers and citizens to be active participants in modelling and analysis.

\section{Conclusions}

The UN sustainable development goals provide a framework to guide countries in building a prosperous and environmentally secure future. Through an in-depth analysis of the 17 SDGs, we have shown that there is a need to incorporate many synergies and trade-offs inherent in the goals into systems models. This will help ensure that addressing one goal does not inadvertently impact the ability to achieve others. Though some models are starting to incorporate climate impacts and land and water use in their analysis, few models go beyond this scope to address the many different interactions envisioned by the SDGs. Modellers should work on designing models that can incorporate and describe the SDGs such that policymakers can consider these aspects when using model outputs.

Table 2 summarizes which goals need to be included when expanding the modelling nexus beyond climate, land, energy and water. Specifically, we have rated seven goals as being important to incorporate into modelling frameworks, namely goal 1 (no poverty), goal 2 (zero hunger), goal 3 (good health and well-being), goal 6 (clean water and sanitation), goal 7 (affordable and clean energy), goal 13 (climate action), and goal 15 (life on land). As such, a nexus analysis that incorporates climate, land, energy and water, as well as economic well-being, health benefits and impacts and considers land in terms of both food production and in terms of sustaining ecological diversity and natural capital would provide more nuanced systems analysis.
Luckily, most of these goals were also rated either easy or relatively easy to incorporate into modelling frameworks. Addressing poverty requires some additional consideration of equality, both in terms of goal 5 (gender equality), and goal 10 (reduced inequalities) and that poses some challenges for system models. Addressing goal 13 requires some consideration of both sides of the climate change challenge, namely adaptation and mitigation, making it slightly more challenging to incorporate. However, none of the goals rated as critically important to model were rated as impossible or unclear how this could be modelled. Expanding the nexus should, therefore, be feasible and beneficial.

Finally, we note the importance of open-source models, open data, well documented processes and transparent analysis for addressing goals 16 and 17 . Without this it is unclear how these goals can be met, nor how policymakers and citizens can have access to the modelling outputs. Transparency, along with open models and data, will allow countries to build their own models and call in the expertise to partner with them rather than being tied to commercial operators whose models are opaque and inaccessible.

\begin{abstract}
Abbreviations
CIMS: A partial equilibrium model used to analyse different policies on societal outcomes (not an acronym); CLEWs: Climate, Land, Energy and Water Systems Model; GCAM: Global Change Assessment Model; NEST: Nexus Solutions Tool; PLEXOS: A power systems/capacity expansion model (not an acronym); UN: United Nations; SDGs: Sustainable development goals.
\end{abstract}

\section{Acknowledgements}

Not applicable.

Authors' contributions

All authors discussed the approach and the concept of including the SDGs in energy system modelling. T.N. drafted the manuscript and all authors contributed their expertise, interpretation, and suggestions on the ideas in the manuscript. All authors reviewed and approved the submitted version of the manuscript.

\section{Funding}

This analysis was undertaken by the authors without any external funding sources.

Availability of data and materials

Not applicable.

Ethical approval and consent to participate

Not applicable.

\section{Consent for publication}

Not applicable.

\section{Competing interests}

The authors have no competing interests to declare.

\section{Author details}

${ }^{1}$ School of Sustainable Energy Engineering, Faculty of Applied Science, Simon Fraser University, 10285 University Dr., Surrey, BC V3T 4B7, Canada. ${ }^{2}$ Faculty of Environment, Pacific Water Research Center, Simon Fraser University, Burnaby, BC, Canada. 
Received: 5 August 2020 Accepted: 3 December 2020

Published online: 05 January 2021

\section{References}

1. United Nations. Sustainable development goals. https://sustainabledeve lopment.un.org/sdgs. Accessed 4 Dec 2018.

2. McCollum DL et al (2018) Connecting the sustainable development goals by their energy inter-linkages. Environ Res Lett 13(3):033006. https://doi. org/10.1088/1748-9326/aaafe3

3. Engström RE, Howells M, Destouni G, Bhatt V, Bazilian M, Rogner $\mathrm{H}-\mathrm{H}$ (2017) Connecting the resource nexus to basic urban service provisionwith a focus on water-energy interactions in New York City. Sustain Cities Soc 31:83-94. https://doi.org/10.1016/j.scs.2017.02.007

4. Welsch M et al (2014) Adding value with CLEWS - modelling the energy system and its interdependencies for Mauritius. Appl Energy 113:14341445. https://doi.org/10.1016/j.apenergy.2013.08.083

5. Saif Y, Almansoori A (2017) An optimization framework for the climate, land, energy, and water (CLEWS) Nexus by a discrete optimization model. Energy Proc 105:3232-3238. https://doi.org/10.1016/j.egypro.2017.03.714

6. Vinca A, Parkinson S, Byers E, Burek P. Achieving climate-land-energywater sustainable development goals in the Indus Basin. Presented at the European Geosciences Union (EGU) General Assembly 2019, Vienna, Austria. 2019. https://www.egu2019.eu/. Accessed 27 Oct 2019.

7. Vinca A, et al. The Nexus Solutions Tool (NEST): an open platform for optimizing multi-scale energy-water-land system transformations. In: Geoscientific model development discussions. 2019. p. 1-33. https://doi. org/10.5194/gmd-2019-134.

8. Stylianopoulou KG, Papapostolou CM, Kondili EM (2020) Water-energyfood Nexus: a focused review on integrated methods. Environ Sci Proc 2(1):46. https://doi.org/10.3390/environsciproc2020002046

9. Brinkerink $M$. Detailed power system analysis of IAM $1.5^{\circ} \mathrm{C}-2^{\circ} \mathrm{C}$ scenarios with an hourly global electricity model. In: Presented at the twelfth annual meeting of the integrated assessment modelling consortium, Tsukuba. 2019.

10. GCAM Documentation. GCAM v5.2 Documentation: Global Change Assessment Model (GCAM). GCAM Documentation. 2019. http://jgcri github.io/gcam-doc/. Accessed 30 Dec 2019.

11. Deane JP, Drayton G, Gallachóir BPÓ (2014) The impact of sub-hourly modelling in power systems with significant levels of renewable generation. Appl Energy 113:152-158. https://doi.org/10.1016/j.apene rgy.2013.07.027

12. García-Gusano D, Iribarren D, Martín-Gamboa M, Dufour J, Espegren K, Lind A (2016) Integration of life-cycle indicators into energy optimisation models: the case study of power generation in Norway. J Clean Prod 112(Part 4):2693-2696. https://doi.org/10.1016/j.jclepro.2015.10.075

13. Galli A, Wiedmann T, Ercin E, Knoblauch D, Ewing B, Giljum S (2012) Integrating ecological, carbon and water footprint into a 'Footprint Family' of indicators: definition and role in tracking human pressure on the planet. Ecol Ind 16:100-112. https://doi.org/10.1016/j.ecolind.2011.06.017

14. Galli A, Weinzettel J, Cranston G, Ercin E (2013) A Footprint Family extended MRIO model to support Europe's transition to a One Planet Economy. Sci Total Environ 461-462:813-818. https://doi.org/10.1016/j. scitotenv.2012.11.071

15. Fang K, Heijungs R, de Snoo GR (2014) Theoretical exploration for the combination of the ecological, energy, carbon, and water footprints: overview of a footprint family. Ecol Ind 36:508-518. https://doi. org/10.1016/j.ecolind.2013.08.017

16. Fang K et al (2016) The footprint's fingerprint: on the classification of the footprint family. Curr Opin Environ Sustain 23:54-62. https://doi. org/10.1016/j.cosust.2016.12.002

17. Rushforth RR, Adams EA, Ruddell BL (2013) Generalizing ecological, water and carbon footprint methods and their worldview assumptions using embedded resource accounting. Water Resour Ind 1-2:77-90. https://doi. org/10.1016/j.wri.2013.05.001

18. International Council for Science. A guide to SDG interactions: from science to implementation. In: Griggs DJ, Nilsson M, Stevance A, McCollum D, editors. International Council for Science (ICSU), Paris. 2017. https://doi. org/10.24948/2017.01.
19. van Soest HL et al (2019) Analysing interactions among sustainable development goals with integrated assessment models. Glob Transit 1:210-225. https://doi.org/10.1016/j.glt.2019.10.004

20. Pradhan P, Costa L, Rybski D, Lucht W, Kropp JP (2017) A systematic study of sustainable development goal (SDG) interactions. Earth's Future 5(11):1169-1179. https://doi.org/10.1002/2017EF000632

21. Félix EGS, Belo TF (2019) The impact of microcredit on poverty reduction in eleven developing countries in south-east Asia. J Multinatl Financ Manag 52-53:100590. https://doi.org/10.1016/j.mulfin.2019.07.003

22. Olopade BC, Okodua H, Oladosun M, Asaleye AJ (2019) Human capital and poverty reduction in OPEC member-countries. Heliyon 5(8):e02279. https://doi.org/10.1016/j.heliyon.2019.e02279

23. Medeiros M, Barbosa RJ, Carvalhaes F (2019) Educational expansion, inequality and poverty reduction in Brazil: a simulation study. Res Social Stratif Mobil. https://doi.org/10.1016/j.rssm.2019.100458

24. Martin-Hurtado R et al (2017) Assessment of the water-food-energy ecosystems Nexus and benefits of transboundary cooperation in the Drina River Basin. UN ECE, New York/Geneva

25. Almulla Y, Ramos E, Gardumi F, Taliotis C, Lipponen A, Howells M (2018) The role of energy-water nexus to motivate transboundary cooperation. Int J Sustain Energy Plan Manag 18:3-28. https://doi.org/10.5278/ijsep m.2018.18.2

26. Hermann S et al (2012) Climate, land, energy and water (CLEW) interlinkages in Burkina Faso: an analysis of agricultural intensification and bioenergy production. Nat Resour Forum 36(4):245-262. https://doi.org/1 0.1111/j.1477-8947.2012.01463.x

27. Engström R, Howells M, Mörtberg U, Destouni G (2018) Multi-functionality of nature-based and other urban sustainability solutions: New York City study. Land Degrad Dev. https://doi.org/10.1002/ldr.3113

28. IIASA/FAO. Global Agro-ecological Zones (GAEZ v3.0). IIASA and FAO, Laxenburg, Austria (IIASA) and Rome, Italy (FAO). 2012.

29. Hensher M (2020) Incorporating environmental impacts into the economic evaluation of health care systems: perspectives from ecological economics. Resour Conserv Recycl 154:104623. https://doi.org/10.1016/j. resconrec.2019.104623

30. Lott MC, Pye S, Dodds PE (2017) Quantifying the co-impacts of energy sector decarbonisation on outdoor air pollution in the United Kingdom. Energy Policy 101:42-51. https://doi.org/10.1016/j.enpol.2016.11.028

31. Shih Y-H, Tseng C-H (2014) Cost-benefit analysis of sustainable energy development using life-cycle co-benefits assessment and the system dynamics approach. Appl Energy 119:57-66. https://doi.org/10.1016/j. apenergy.2013.12.031

32. Zvingilaite E. Health externalities and heat savings in energy system modelling. Ph.D., Technical University of Denmark (DTU), Denmark. 2013.

33. Nawab A, Liu G, Meng F, Hao Y, Zhang Y (2019) Urban energy-water nexus: spatial and inter-sectoral analysis in a multi-scale economy. Ecol Model 403:44-56. https://doi.org/10.1016/j.ecolmodel.2019.04.020

34. Giurco D, Cohen B, Langham E, Warnken M (2011) Backcasting energy futures using industrial ecology. Technol Forecast Soc Chang 78(5):797818. https://doi.org/10.1016/j.techfore.2010.09.004

35. Jaccard M (2009) Combining top down and bottom up in energy economy models. In: Evans J, Hunt LC (eds) International handbook on the economics of energy. Edward Elgar, Cheltenham, pp 311-331

36. Murphy R, Rivers N, Jaccard M (2007) Hybrid modeling of industrial energy consumption and greenhouse gas emissions with an application to Canada. Energy Econ 29(4):826-846. https://doi.org/10.1016/j.eneco 2007.01.006

37. Murphy R, Jaccard M (2011) Energy efficiency and the cost of GHG abatement: a comparison of bottom-up and hybrid models for the US. Energy Policy 39(11):7146-7155. https://doi.org/10.1016/j.enpol.2011.08.033

38. Brookings Institute Africa Growth Initiative. Foresight Africa: Top priorities for the continent 2020-2030. Washington, D.C.: Brookings Institute; 2020. https://www.brookings.edu/wp-content/uploads/2020/01/ForesightA frica2020_20200110.pdf. Accessed 13 Jan 2020.

39. Pfenninger S, DeCarolis J, Hirth L, Quoilin S, Staffell I (2017) The importance of open data and software: is energy research lagging behind? Energy Policy 101:211-215. https://doi.org/10.1016/j.enpol.2016.11.046

40. Pfenninger $\mathrm{S}$ et al (2018) Opening the black box of energy modelling: strategies and lessons learned. Energy Strategy Rev 19:63-71. https://doi. org/10.1016/j.esr.2017.12.002 
41. Gardumi F et al (2018) From the development of an open-source energy modelling tool to its application and the creation of communities of practice: the example of OSeMOSYS. Energy Strategy Rev 20:209-228. https://doi.org/10.1016/j.esr.2018.03.005

42. United Nations Department of Economic and Social Affairs. Capacity Development at the United Nations. https://www.un.org/development/ desa/capacity-development/. Accessed 29 Jan 2020.

\section{Publisher's Note}

Springer Nature remains neutral with regard to jurisdictional claims in published maps and institutional affiliations.
Ready to submit your research? Choose BMC and benefit from:

- fast, convenient online submission

- thorough peer review by experienced researchers in your field

- rapid publication on acceptance

- support for research data, including large and complex data types

- gold Open Access which fosters wider collaboration and increased citations

- maximum visibility for your research: over $100 \mathrm{M}$ website views per year

At BMC, research is always in progress.

Learn more biomedcentral.com/submissions 